\title{
Prospective Study of Central versus Peripheral Obesity in Total Knee Arthroplasty
}

\author{
John G. Armstrong, BA ${ }^{1}$, Tyler R. Morris, $\mathrm{MD}^{1}$, Ronnie Sebro, $\mathrm{MD}, \mathrm{PhD}^{1,2,3}$, Craig L. Israelite, $\mathrm{MD}^{1}$, and \\ Atul F. Kamath, MD ${ }^{1}$ \\ ${ }^{1}$ Department of Orthopedic Surgery, University of Pennsylvania, Philadelphia, PA; ${ }^{2}$ Department of Radiology, University of Pennsylvania, Philadelphia, PA; ${ }^{3}$ Department \\ of Genetics, University of Pennsylvania, Philadelphia, PA, USA
}

\begin{abstract}
Purpose: Body mass index (BMI) is often used to predict surgical difficulty in patients receiving total knee arthroplasty (TKA); however, BMI neglects variation in the central versus peripheral distribution of adipose tissue. We sought to examine whether anthropometric factors, rather than BMI alone, may serve as a more effective indication of surgical difficulty in TKA.

Materials and Methods: We prospectively enrolled 67 patients undergoing primary TKA. Correlation coefficients were used to evaluate the associations of tourniquet time, a surrogate of surgical difficulty, with BMI, pre- and intraoperative anthropometric measurements, and radiographic knee alignment. Similarly, Knee Injury and Osteoarthritis Outcome Score (KOOS) was compared to BMI.

Results: Tourniquet time was significantly associated with preoperative inferior knee circumference $(\mathrm{p}=0.025)$ and ankle circumference $(\mathrm{p}=0.003)$ as well as the intraoperative depth of incision at the quadriceps $(\mathrm{p}=0.014)$. BMI was not significantly associated with tourniquet time or any of the radiographic parameters or KOOS scores.

Conclusions: Inferior knee circumference, ankle circumference, and depth of incision at the quadriceps (measures of peripheral obesity) are likely better predictors of surgical difficulty than BMI. Further study of alternative surgical indicators should investigate patients that may be deterred from TKA for high BMI, despite relatively low peripheral obesity.
\end{abstract}

Keywords: Knee, Arthroplasty, Obesity, Anthropometry

\section{Introduction}

Obesity afflicts one in three people in the United States, causing a variety of major health concerns, namely accelerated knee osteoarthritis $(\mathrm{OA})^{1-3)}$. The literature is largely in agreement that obesity causes accelerated knee OA. Many studies have found a strong association between obesity and accelerated joint $\mathrm{OA}$ with approximately half of total joint arthroplasty performed for patients body mass index $(\mathrm{BMI}) \geq 30^{4-7)}$. Despite a growing demand

Received April 13, 2018; Revised June 13, 2018; Accepted June 28, 2018 Correspondence to: Atul F. Kamath, MD

Department of Orthopedic Surgery, University of Pennsylvania, 3737

Market Street, Philadelphia, PA 19104, USA

Tel: +1-215-687-8169, Fax: +1-215-829-2492

E-mail: akamath@post.harvard.edu

This is an Open Access article distributed under the terms of the Creative Commons Attribution Non-Commercial License (http://creativecommons.org/licenses/by-nc/4.0/) which permits unrestricted non-commercial use, distribution, and reproduction in any medium, provided the original work is properly cited. for total knee arthroplasty (TKA) in obese patients, defined as having a BMI over $30^{7-9)}$, surgeons face many intraoperative challenges, such as accurate prosthesis alignment, exposure, and instrument access.

While multiple studies have sought to study association between BMI and surgical outcomes, our study takes a more comprehensive approach by using a robust assortment of anthropometric limb measurements. Using more limb-specific assessment criteria, rather than a global BMI approach, we believe that the relationship between body habitus and surgical outcomes may be more accurately predicted. For example, a large limb (increased peripheral obesity) may be more of a surgical challenge than a small limb in a patient with predominantly central obesity. While BMI is commonly used as a method to predict surgical difficulty, this method fails to consider variation in central versus peripheral distribution of adipose tissue, often referred to in layman's terms as the "apple" versus "pear" body types, respectively ${ }^{7-9)}$. Despite previous studies showing an increased rate of complications in obese patients, few have assessed the anatomic-specific distri- 
bution of adipose tissue and its effect on surgical difficulty ${ }^{10-12)}$. We hypothesized that anthropometric factors would be more predictive of surgical difficulty than BMI alone. Thus, we sought to analyze anthropometric measurements, radiographic knee alignment, and patient-reported scores to understand the relationship between body fat distribution and surgical complexity. Our hypothesis suggests that central versus peripheral adipose distribution would more closely relate to surgical difficulty when compared to BMI.

\section{Materials and Methods}

Seventy-eight patients were prospectively enrolled at a single high-volume (total volume of primary arthroplasty greater than 1,000 cases per year) arthroplasty referral institution, with 67 patients completing primary unilateral or staged bilateral TKA for knee OA between June 2015 and June 2016. Exclusion criteria were age less than 18 years at the time of surgery, revision arthroplasty indication, simultaneous bilateral primary knee arthroplasty, post-traumatic arthritis, and retained hardware. Enrolled patients were stratified into one of four classes according to the World Health Organization (WHO) schema on BMI: not obese $(<30.0)$, class I (30.0-34.9), class II (35.0-39.9), and class III ( $>40.0)$.

All anthropometric measurements, except those carried out intraoperatively, were obtained at the preoperative visit and within four weeks of the surgery. Preoperative anthropometric measurements were taken with an inelastic, flexible tape measure

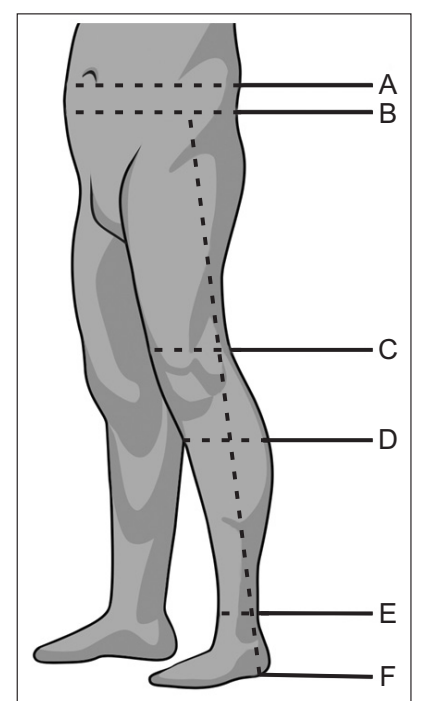

Fig. 1. Preoperative measurement diagram. A: abdominal girth at umbilicus, B: abdominal girth at anterior-superior iliac spine (ASIS), C: superior knee circumference, D: inferior knee circumference, E: ankle circumference, F: leg length from ASIS to sole of heel. by trained study personnel according to Fig. 1. Anthropometric measurements included abdominal girth (measured around both the umbilicus and anterior-superior iliac spine [ASIS]), superior knee circumference (measured four centimeters superior to the patella), inferior knee circumference (measured four centimeters inferior to the patella), ankle circumference (measured two centimeters superior to the malleoli), and leg length (measured from ASIS to sole of heel). Three indexes were created for these anthropometric measurements: superior knee index (leg length/ superior knee circumference), inferior knee index (leg length/ inferior knee circumference), and superior knee index/inferior knee index. Goniometric measurements included an initial preoperative range of motion (ROM).

Intraoperative anthropometric measurements were taken with an inelastic ruler by trained study personnel according to Fig. 2. Anthropometric measurements of the incision included depth of incision (measured in millimeters in two areas: the quadriceps tendons and the midpoint of the patella) and length of incision (measured in centimeters at closure). Goniometric measurements for ROM were performed similarly to preoperation in the supine position. Tourniquet time was determined based on the time from inflation of the cuff just prior to incision to the time of deflation of the cuff immediately after incision closure.

Pre- and postoperative radiographic measurements were used to determine the femorotibial alignment. Alignment was evaluated using a system as previously described ${ }^{13)}$.

Knee Injury and Osteoarthritis Outcome Score (KOOS) surveys were obtained at the preoperative visit and within four weeks of the

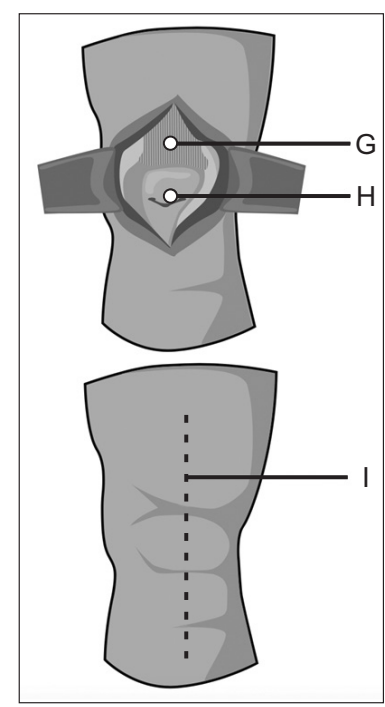

Fig. 2. Intraoperative measurement diagram. G: depth of incision at quadriceps, $\mathrm{H}$ : depth of incision at patella, I: length of incision. 
surgery. Patient-reported scores were recorded for each of five subcategories to assess the knee and associated conditions on a scale of $0-100$, with zero indicating the most severe knee problems.

The mean and standard deviation were calculated for demographic and clinical characteristics, anthropometric measurements, radiographic knee alignments, and KOOS categories within each WHO obesity BMI class. Associations between anthropometric measurements including BMI and tourniquet time were evaluated using Pearson correlation coefficients. Linear regression analysis was used to determine the correlation coefficient, $r$, and the significance when comparing BMI and each anthropometric measurement to tourniquet time. The type I error rate $\alpha$ was set at 0.05 and used to determine the confidence interval. All statistical tests were two-sided, and p-values $<0.05$ were considered statistically significant. Statistics were calculated using statistical software (R ver. 3.4; https://www.r-project.org).

Table 1. Patient Characteristics

\begin{tabular}{lccccc}
\hline \multirow{2}{*}{ Characteristic } & \multicolumn{5}{c}{ BMI class } \\
\cline { 2 - 6 } & Not obese $(\mathrm{n}=24)$ & Class I $(\mathrm{n}=11)$ & Class II $(\mathrm{n}=19)$ & Class III $(\mathrm{n}=13)$ & Total $(\mathrm{n}=67)$ \\
\hline Age $(\mathrm{yr})$ & $64.75 \pm 8.27$ & $62.55 \pm 7.70$ & $66.47 \pm 10.22$ & $60.15 \pm 8.06$ & $63.99 \pm 8.85$ \\
No. of males (\%) & $10(41.67)$ & $8(72.73)$ & $4(21.05)$ & $5(38.46)$ & $27(40.30)$ \\
Height (in) & $66.48 \pm 3.87$ & $67.82 \pm 4.45$ & $65.37 \pm 3.50$ & $66.12 \pm 4.71$ & $66.31 \pm 4.03$ \\
Weight $(\mathrm{lb})$ & $172.2 \pm 29.49$ & $213.4 \pm 20.75$ & $228.5 \pm 27.08$ & $279.5 \pm 50.93$ & $215.3 \pm 50.76$ \\
BMI (kg/m $\left.{ }^{2}\right)$ & $27.23 \pm 2.85$ & $32.64 \pm 1.72$ & $37.48 \pm 1.76$ & $44.62 \pm 3.72$ & $34.40 \pm 7.01$ \\
Tourniquet time (min) & $66.46 \pm 16.89$ & $75.55 \pm 17.15$ & $77.00 \pm 17.95$ & $73.38 \pm 19.48$ & $72.28 \pm 17.93$ \\
\hline
\end{tabular}

Values are presented as mean \pm standard deviation and recorded preoperatively in the clinic within four weeks of surgical date.

BMI: body mass index.

Table 2. Preoperative Anthropometric Measurement in Relation to Tourniquet Time

\begin{tabular}{|c|c|c|c|c|c|c|c|c|}
\hline \multirow[t]{2}{*}{ Variable } & \multicolumn{5}{|c|}{ BMI class } & \multicolumn{3}{|c|}{$\begin{array}{c}\text { Tourniquet time vs. Preoperative } \\
\text { measurement (total cohort) }\end{array}$} \\
\hline & Not obese $(n=24)$ & Class I ( $\mathrm{n}=11)$ & Class II $(n=19)$ & Class III $(n=13)$ & Total $(\mathrm{n}=67)$ & $\mathrm{r}$ & $95 \% \mathrm{CI}$ & $\mathrm{p}$-value \\
\hline BMI $\left(\mathrm{kg} / \mathrm{m}^{2}\right)$ & $27.23 \pm 2.85$ & $32.64 \pm 1.72$ & $37.48 \pm 1.76$ & $44.62 \pm 3.72$ & $34.40 \pm 7.01$ & 0.01 & -0.22 to 1.05 & 0.202 \\
\hline $\begin{array}{l}\text { Abdominal girth at } \\
\text { umbilicus }(\mathrm{cm})\end{array}$ & $104.42 \pm 13.47$ & $118.73 \pm 5.06$ & $126.79 \pm 9.35$ & $141.31 \pm 14.09$ & $120.27 \pm 17.84$ & 0.07 & -0.17 to 0.30 & 0.580 \\
\hline $\begin{array}{l}\text { Abdominal girth at } \\
\text { ASIS }(\mathrm{cm})\end{array}$ & $106.58 \pm 9.95$ & $121.00 \pm 10.40$ & $128.47 \pm 11.50$ & $135.62 \pm 11.35$ & $120.79 \pm 15.62$ & 0.09 & -0.16 to 0.32 & 0.486 \\
\hline $\begin{array}{l}\text { Superior knee } \\
\text { circumference }(\mathrm{cm})\end{array}$ & $42.42 \pm 4.75$ & $50.55 \pm 5.15$ & $52.68 \pm 3.20$ & $57.38 \pm 9.60$ & $49.57 \pm 8.06$ & 0.19 & -0.05 to 0.41 & 0.116 \\
\hline $\begin{array}{l}\text { Inferior knee } \\
\text { circumference }(\mathrm{cm})\end{array}$ & $37.00 \pm 4.20$ & $42.45 \pm 4.50$ & $43.21 \pm 3.10$ & $46.38 \pm 5.65$ & $41.48 \pm 5.54$ & 0.27 & 0.04 to 0.48 & $0.025^{\mathrm{a})}$ \\
\hline Ankle circumference $(\mathrm{cm})$ & $22.71 \pm 2.46$ & $26.00 \pm 3.49$ & $26.79 \pm 3.90$ & $27.31 \pm 4.71$ & $25.30 \pm 4.01$ & 0.53 & 0.13 to 0.55 & $0.003^{\mathrm{a})}$ \\
\hline $\begin{array}{l}\text { Leg length from ASIS to } \\
\text { sole of heel }(\mathrm{cm})\end{array}$ & $101.17 \pm 5.51$ & $103.27 \pm 5.04$ & $99.26 \pm 7.44$ & $100.92 \pm 7.98$ & $100.93 \pm 6.55$ & 0.08 & -0.16 to 0.31 & 0.519 \\
\hline $\begin{array}{l}\text { Superior knee index (leg } \\
\text { length/superior knee } \\
\text { circumference) }\end{array}$ & $2.42 \pm 0.36$ & $2.06 \pm 0.22$ & $1.89 \pm 0.20$ & $1.81 \pm 0.34$ & $2.09 \pm 0.39$ & -0.16 & -0.38 to 0.09 & 0.207 \\
\hline $\begin{array}{l}\text { Inferior knee index (leg } \\
\text { length/inferior knee } \\
\text { circumference) }\end{array}$ & $2.77 \pm 0.33$ & $2.46 \pm 0.29$ & $2.30 \pm 0.17$ & $2.21 \pm 0.33$ & $2.48 \pm 0.36$ & -0.20 & -0.42 to 0.04 & 0.100 \\
\hline Superior/inferior knee index & $1.15 \pm 0.07$ & $1.19 \pm 0.06$ & $1.22 \pm 0.10$ & $1.23 \pm 0.10$ & $1.19 \pm 0.09$ & -0.04 & -0.28 to 0.20 & 0.733 \\
\hline
\end{tabular}

Values are presented as mean \pm standard deviation.

BMI: body mass index, CI: confidence interval, ASIS: anterior-superior iliac spine.

${ }^{a)}$ Significant difference. 


\section{Armstrong et al. Prospective Study of Central vs. Peripheral Obesity in TKA}

\section{Results}

Demographic and clinical characteristic data for the $67 \mathrm{pa}-$ tients undergoing TKA is presented in Table 1 . There were 27 males and 40 females with an average age at time of surgery of $63.99 \pm 8.85$ years. The average BMI for the overall sample was $34.40 \pm 7.01 \mathrm{~kg} / \mathrm{m}^{2}$, and the average tourniquet time was $72.28 \pm 17.93$ minutes. The number of patients in each category of BMI is shown in Table 1 .
In Tables $2-4$, the mean and standard deviation was determined for each preoperative measurement for each BMI class. There was no significant difference comparing BMI to tourniquet time. Two anthropometric measurements, inferior knee and ankle circumferences, had a significant relationship to tourniquet time, with p-values of 0.025 and 0.003 , respectively. Intraoperative anthropometric measurements included incision depth in two areas, incision length, and the change in ROM. The depth of the incision at the quadriceps was the only measurement with a sig-

Table 3. Intraoperative Anthropometric Measurement in Relation to Tourniquet Time

\begin{tabular}{|c|c|c|c|c|c|c|c|c|}
\hline \multirow[t]{2}{*}{ Variable } & \multicolumn{5}{|c|}{ BMI class } & \multicolumn{3}{|c|}{$\begin{array}{l}\text { Tourniquet time vs. Intraoperative } \\
\text { measurement (total cohort) }\end{array}$} \\
\hline & Not obese $(n=12)$ & Class I $(\mathrm{n}=7)$ & Class II $(\mathrm{n}=11)$ & Class III (n=10) & Total $(\mathrm{n}=40)$ & $\mathrm{r}$ & $95 \% \mathrm{CI}$ & p-value \\
\hline $\begin{array}{l}\text { Depth of incision at } \\
\text { quadriceps }(\mathrm{mm})\end{array}$ & $12.92 \pm 3.00$ & $15.29 \pm 3.20$ & $20.62 \pm 13.28$ & $25.20 \pm 10.97$ & $18.52 \pm 10.07$ & 0.38 & 0.08 to 0.62 & $0.014^{\mathrm{a})}$ \\
\hline $\begin{array}{l}\text { Depth of incision at patella } \\
(\mathrm{mm})\end{array}$ & $5.67 \pm 2.27$ & $5.57 \pm 1.51$ & $9.68 \pm 7.75$ & $11.70 \pm 3.92$ & $8.26 \pm 5.26$ & 0.25 & -0.07 to 0.52 & 0.119 \\
\hline Length of incision $(\mathrm{cm})$ & $15.02 \pm 0.95$ & $16.50 \pm 1.04$ & $17.41 \pm 2.80$ & $17.50 \pm 3.61$ & $16.56 \pm 2.57$ & 0.15 & -0.17 to 0.44 & 0.343 \\
\hline Change in range of motion $\left({ }^{\circ}\right)$ & $+20.83 \pm 18.16$ & $+23.57 \pm 22.02$ & $+38.45 \pm 20.02$ & $+29.80 \pm 20.63$ & $+28.40 \pm 20.48$ & 0.16 & -0.16 to 0.45 & 0.325 \\
\hline
\end{tabular}

Values are presented as mean \pm standard deviation.

BMI: body mass index, CI: confidence interval.

${ }^{\text {a) }}$ Significant difference.

Table 4. Radiographic Knee Alignment in Relation to Tourniquet Time

\begin{tabular}{|c|c|c|c|c|c|c|c|c|}
\hline \multirow[t]{2}{*}{ Variable } & \multicolumn{5}{|c|}{ BMI class } & \multicolumn{3}{|c|}{$\begin{array}{c}\text { Tourniquet time vs. Femorotibia } \\
\text { alignment (total cohort) }\end{array}$} \\
\hline & Not obese $(n=18)$ & Class I $(n=7)$ & Class II $(n=16)$ & Class III $(n=9)$ & Total $(\mathrm{n}=50)$ & $\mathrm{r}$ & $95 \% \mathrm{CI}$ & $\mathrm{p}$-value \\
\hline Preoperative knee alignment $\left({ }^{\circ}\right)$ & $184.1 \pm 7.7$ & $197.2 \pm 3.2$ & $180.6 \pm 6.8$ & $180.6 \pm 9.2$ & $182.9 \pm 8.5$ & 0.02 & -0.26 to 0.30 & 0.900 \\
\hline $\begin{array}{l}\text { Improvement in femorotibial } \\
\text { alignment }\left(^{\circ}\right)\end{array}$ & $+2.33 \pm 5.10$ & $+8.57 \pm 6.75$ & $+3.94 \pm 4.28$ & $+3.67 \pm 5.32$ & $+3.96 \pm 5.37$ & 0.20 & -0.08 to 0.45 & 0.166 \\
\hline
\end{tabular}

Values are presented as mean \pm standard deviation.

BMI: body mass index, CI: confidence interval.

Table 5. Body Mass Index (BMI) versus Knee Injury and Osteoarthritis Outcome Score (KOOS)

\begin{tabular}{|c|c|c|c|c|c|c|c|c|}
\hline \multirow{2}{*}{ KOOS category } & \multicolumn{5}{|c|}{ BMI class } & \multicolumn{3}{|c|}{ BMI vs. KOOS (total cohort) } \\
\hline & Not obese $(n=17)$ & Class I (n=9) & Class II $(\mathrm{n}=12)$ & Class III $(n=11)$ & Total $(\mathrm{n}=49)$ & $\mathrm{r}$ & $95 \% \mathrm{CI}$ & $\mathrm{p}$-value \\
\hline Symptom & $44.33 \pm 16.75$ & $53.17 \pm 17.99$ & $44.35 \pm 21.07$ & $46.10 \pm 21.95$ & $46.36 \pm 19.00$ & 0.06 & -0.23 to 0.33 & 0.702 \\
\hline Pain & $42.65 \pm 16.75$ & $44.44 \pm 13.54$ & $43.75 \pm 14.85$ & $41.67 \pm 16.80$ & $43.03 \pm 15.31$ & -0.03 & -0.31 to 0.26 & 0.858 \\
\hline $\begin{array}{l}\text { Function in daily } \\
\text { living }\end{array}$ & $51.56 \pm 20.08$ & $62.25 \pm 15.69$ & $56.99 \pm 11.44$ & $48.93 \pm 16.63$ & $54.26 \pm 17.18$ & -0.04 & -0.31 to 0.25 & 0.810 \\
\hline $\begin{array}{c}\text { Function in sport } \\
\text { and recreation }\end{array}$ & $82.65 \pm 28.46$ & $100 \pm 0$ & $98.75 \pm 3.11$ & $91.36 \pm 22.81$ & $91.73 \pm 20.86$ & 0.23 & -0.06 to 0.48 & 0.113 \\
\hline $\begin{array}{l}\text { Knee-related } \\
\text { quality of life }\end{array}$ & $30.15 \pm 19.67$ & $30.56 \pm 16.37$ & $28.65 \pm 18.36$ & $23.86 \pm 11.12$ & $28.44 \pm 16.83$ & -0.14 & -0.41 to 0.15 & 0.336 \\
\hline
\end{tabular}

Values are presented as mean \pm standard deviation. There was no significant difference when comparing KOOS to BMI for each of the five categories. CI: confidence interval. 
nificant correlation with tourniquet time.

Radiographic measurement values for the preoperative knee alignment, as well as the improvement in femorotibial alignment (change in alignment between preoperative and postoperative $\mathrm{X}$ rays) showed no significant relationship toward tourniquet time.

The KOOS scores for the cohort are shown in Table 5. Mean reported scores and their standard deviations were compared among BMI classes. There was no significant difference when comparing KOOS to BMI for each of the five categories: symptoms ( $p=0.702)$, pain ( $p=0.858)$, function in daily living $(p=0.810)$, function in sport and recreation $(\mathrm{p}=0.113)$, and knee-related quality of life $(\mathrm{p}=0.336)$.

\section{Discussion}

BMI, as a global measure of obesity, fails to consider patients who have adipose tissue concentrated either centrally (appleshaped body) or peripherally (pear-shaped body). Thus, this prospective study suggests that distribution of body fat has clinical implications for surgical procedures in the extremities like TKA. As we hypothesized, BMI should not be the sole indicator of surgical difficulty; local extremity anthropometric measurements were more indicative of surgical difficulty.

Our results suggest that certain lower extremity anthropometric measurements are more indicative of tourniquet time than BMI. In particular, the preoperative measurements, inferior knee and ankle circumferences, were both statistically related to increased tourniquet time. Fat deposition in these regions directly influence the amount of surgical exposure that may be required during TKA. Additionally, intra-operative measurement of the depth of the incision at the quadriceps tendon was a significant indicator of increased tourniquet time, while all other intraoperative measurements were not. This may be due to the fact that the quadriceps tendon is the location most proximate to TKA exposure, when compared to the other measures. Surgical exposure is limited by the mobility of the extensor mechanism, which is directly influenced by the extent of the quadriceps tendon arthrotomy incision and time required to safely expose the knee joint.

Our findings indicate that higher classes of BMI showed increased variability between body measurements. Therefore, more obese patients, who may be at highest risk of complications ${ }^{10-12)}$, had the largest variance in peripheral adipose fat tissue. However, patients with lower scores in peripheral measurements, such as inferior knee circumference, retained higher BMIs based on their central obesity. This correlation held despite the fact that overall BMIs did not correlate with increased surgical difficulty. BMI in and of itself did not correlate with increased tourniquet time, supporting the conclusion by Lozano et al. ${ }^{14)}$. Interestingly, in higher BMI classes, the patients with lower peripheral measurements (which correspond to improved tourniquet times) may have increased central obesity and higher BMIs. As we hypothesized, BMI should not be the sole indicator of surgical difficulty, as local extremity anthropometric measurements were more indicative of surgical difficulty.

Reliance on anthropometric measures in other clinical scenarios provides important indications. For example, central obesity measures such as waist circumference and waist-to-hip ratio have been proven as better indicators of diabetes and cardiovascular diseases than $\mathrm{BMI}^{15)}$. BMI reduces body composition into a single value, neglecting fat-free mass, which is beneficial to tibial cartilage volume, and fat mass, which is deleterious to weight loading of the joint ${ }^{15)}$. Anthropometric measures, such as those employed in this study, can better be associated for differences in other metrics like fat-free mass and fat mass.

Notwithstanding evidence of increased risk for obese patients undergoing TKA, BMI in isolation may not adequately assess risk stratification for a number of other reasons. BMI was originally developed in the nineteenth century as means of determining obesity in large population samples, rather than individuals ${ }^{16)}$. Despite the index's wide adoption in orthopedic clinics for its simplicity and cost-effectiveness in diagnosis, the WHO maintains that BMI should be used with caution on an individual basis, as it does not accurately account for adipose distribution or health risks in individuals ${ }^{17)}$. Physicians often rely on BMI as a quantitative measure of obesity for surgical difficulty, yet there is no consensus on a cutoff value ${ }^{18)}$. As a result, many patients who may be healthy candidates for TKA are either referred by physicians to seek weight counseling programs or may be denied surgery. Accordingly, Han et al. ${ }^{19)}$ found that groups of patients below and above 25 BMI had similar Knee Society Scores, ROM, patellofemoral symptoms, complication rate, and infection rate five years after TKA surgery. Finally, BMI may misdiagnose individuals as obese who are otherwise healthy candidates for TKA. For instance, nearly half of overweight individuals may be metabolically healthy, despite $29 \%$ class I obesity and 16\% class II/III labeled as obese ${ }^{20)}$.

Importance is placed on precise alignment and balancing of the prosthesis in obese patients due to the weight-bearing demands placed on the joint ${ }^{5,21)}$. With each pound of weight adding a fourfold increase in the load exerted on each knee per step, even small malalignment can be magnified severely and may lead to premature revision $^{22)}$ in an obese population. In a retrospective 
review of knee radiographs, Watts et al. ${ }^{23)}$ found that increased complications and infection were associated with increased anterior knee subcutaneous fat thickness as measured on lateral knee radiographs. Radiographic knee alignment results from this study suggest an improvement in alignment across all BMI categories postoperatively. While there was no significance in relation to tourniquet time for both BMI and improvement in femorotibial alignment of the knee, we did find that class I had the greatest improvement in alignment of $8.57^{\circ}$. In our study, we did not find a compromise in accurate postoperative knee alignment based on BMI category, which supports that mechanical alignment can be achieved safely even in more obese patients.

The KOOS measures collected demonstrated no significant difference with respect to BMI for any of the subcategories: symptoms, pain, function in daily living, function in sports and recreation, and knee-related quality of life. This would suggest that BMI alone is not an adequate evaluation technique for patientreported condition. Furthermore, division of the cohort by BMI class revealed a larger variance in symptoms and pain for class III patients than lower BMI classes preoperatively. We suggest that the larger disparity in pain and symptoms in class III patients may be related to differing concentration of adipose tissue either centrally or peripherally resulting in varied levels of joint degeneration. Spicer et al. ${ }^{24)}$ found that patients in class III had the lowest KOOS scores, but the absolute improvement was independent of BMI. This supports our finding that the great variance in fat concentration in class III in particular may have a greater effect on KOOS than BMI. Among obese patients, reported knee-related quality of life showed a dramatic decrease from class I to class III. Although patients with the highest BMI have been traditionally thought of as having the greater risk for surgical complications ${ }^{10-12)}$, extra measures should be taken to assist them, as they suffer from the greatest drop in quality of life scores. Additional evaluation criteria would be beneficial to obese patients, as Ethgen et al. ${ }^{25)}$ found that patients with poorer knee-related quality of life experienced the greatest improvement.

Despite the prospective study design, this study has several limitations. While tourniquet time has been used in the orthopedic field as a useful surrogate to measure surgical difficulty, there are many confounding factors. All surgery was performed in a standardized fashion with the same implants and by fellowshiptrained arthroplasty surgeons with a minimum of 10 years of practice and greater than 300 yearly case volume; however, we acknowledge that surgeon factors may influence particular outcomes. This study may not be generalizable to those patients with post-traumatic arthritis, significant bone loss, prior arthroplasty surgery/revision arthroplasty, simultaneous bilateral primary knee arthroplasty, retained hardware, or mid- and long-term complications, such as deep infection or mechanical prosthesis loosening, as intraoperative surgical difficulty was the primary purpose of our study. In addition, we had no patients with coronal/sagittal plane deformity greater than $15^{\circ}$ and no flexion contractures greater than $15^{\circ}$ preoperatively. Clearly, this would add to our understanding of the relationship between obesity and complications and would be useful in long-term prospective follow-up in large patient cohorts. Other preoperative studies other than anthropometric measurements could be applied to determine fat tissue concentration: dual-energy X-ray absorptiometry, computed axial tomography, magnetic resonance imaging, magnetic resonance spectroscopy, positron emission tomography, and ultrasound ${ }^{26)}$. Furthermore, limb circumference may be dependent on relative concentrations of other tissues, including bone size and muscle volume. In this study, we sought to employ measurements (i.e., anthropometric) that are readily available to any surgeon and obviate the significant costs associated with other advanced imaging modalities.

\section{Conclusions}

In conclusion, BMI alone should not be used as a measure of surgical difficulty, and may actually be a poor indicator when compared to local anthropometric measures. Consideration of central versus peripheral fat concentration can provide a more proscriptive view for surgical risk stratification. Patients that may be denied TKA due to high BMI alone might still be potential surgical candidates when they exhibit suitable peripheral obesity and overall medical conditions optimized. Therefore, surgeons should employ additional measures of risk assessment for surgical difficulty in obese patients apart from BMI alone. Future research should be performed in larger and more diverse patient populations and at longer follow-up in order to further elucidate relationships between body habitus and surgical complexity in TKA.

\section{Conflict of Interest}

No potential conflict of interest relevant to this article was reported.

\section{References}

1. Wagner ER, Kamath AF, Fruth K, Harmsen WS, Berry DJ. Effect of body mass index on reoperation and complications 
after total knee arthroplasty. J Bone Joint Surg Am. 2016;98: 2052-60.

2. Kerkhoffs GM, Servien E, Dunn W, Dahm D, Bramer JA, Haverkamp D. The influence of obesity on the complication rate and outcome of total knee arthroplasty: a meta-analysis and systematic literature review. J Bone Joint Surg Am. 2012; 94:1839-44.

3. Namba RS, Paxton L, Fithian DC, Stone ML. Obesity and perioperative morbidity in total hip and total knee arthroplasty patients. J Arthroplasty. 2005;20(7 Suppl 3):46-50.

4. Foran JR, Mont MA, Etienne G, Jones LC, Hungerford DS. The outcome of total knee arthroplasty in obese patients. J Bone Joint Surg Am. 2004;86:1609-15.

5. Amin AK, Patton JT, Cook RE, Brenkel IJ. Does obesity influence the clinical outcome at five years following total knee replacement for osteoarthritis? J Bone Joint Surg Br. 2006; 88:335-40.

6. Nevitt MC. Obesity outcomes in disease management: clinical outcomes for osteoarthritis. Obes Res. 2002;10 Suppl 1: 33S-37S.

7. Ledford CK, Millikan PD, Nickel BT, Green CL, Attarian DE, Wellman SS, Bolognesi MP, Queen RM. Percent body fat is more predictive of function after total joint arthroplasty than body mass index. J Bone Joint Surg Am. 2016;98:84957.

8. Tomiyama AJ, Hunger JM, Nguyen-Cuu J, Wells C. Misclassification of cardiometabolic health when using body mass index categories in NHANES 2005-2012. Int J Obes (Lond). 2016;40:883-6.

9. Seabolt LA, Welch EB, Silver HJ. Imaging methods for analyzing body composition in human obesity and cardiometabolic disease. Ann N Y Acad Sci. 2015;1353:41-59.

10. Jiganti JJ, Goldstein WM, Williams CS. A comparison of the perioperative morbidity in total joint arthroplasty in the obese and nonobese patient. Clin Orthop Relat Res. 1993; (289):175-9.

11. Amin AK, Clayton RA, Patton JT, Gaston M, Cook RE, Brenkel IJ. Total knee replacement in morbidly obese patients: results of a prospective, matched study. J Bone Joint Surg Br. 2006;88:1321-6.

12. Bordini B, Stea S, Cremonini S, Viceconti M, De Palma R, Toni A. Relationship between obesity and early failure of total knee prostheses. BMC Musculoskelet Disord. 2009;10:29.

13. Kamath AF, Israelite C, Horneff J, Lotke PA. Editorial: What is varus or valgus knee alignment?: a call for a uniform ra- diographic classification. Clin Orthop Relat Res. 2010;468: 1702-4.

14. Lozano LM, Nunez M, Segur JM, Macule F, Sastre S, Nunez E, Suso S. Relationship between knee anthropometry and surgical time in total knee arthroplasty in severely and morbidly obese patients: a new prognostic index of surgical difficulty. Obes Surg. 2008;18:1149-53.

15. Wang Y, Wluka AE, English DR, Teichtahl AJ, Giles GG, O'Sullivan R, Cicuttini FM. Body composition and knee cartilage properties in healthy, community-based adults. Ann Rheum Dis. 2007;66:1244-8.

16. Bogin B, Varela-Silva I. The body mass index: the good, the bad, and the horrid. Bull Anthropol Swiss Soc. 2012;18:5-11.

17. World Health Organization. Obesity: preventing and managing the global epidemic. Geneva: World Health Organization; 2000.

18. Gillespie GN, Porteous AJ. Obesity and knee arthroplasty. Knee. 2007;14:81-6.

19. Han CD, Han CW, Yang IH. The influence of obesity on clinical outcomes after total knee arthroplasty: a five-year minimum follow-up. J Korean Knee Soc. 2008;20:16-21.

20. Tomiyama AJ, Hunger JM, Nguyen-Cuu J, Wells C. Misclassification of cardiometabolic health when using body mass index categories in NHANES 2005-2012. Int J Obes (Lond). 2016;40:883-6.

21. Booth RE Jr. Total knee arthroplasty in the obese patient: tips and quips. J Arthroplasty. 2002;17(4 Suppl 1):69-70.

22. Messier SP, Gutekunst DJ, Davis C, DeVita P. Weight loss reduces knee-joint loads in overweight and obese older adults with knee osteoarthritis. Arthritis Rheum. 2005;52:2026-32.

23. Watts CD, Houdek MT, Wagner ER, Taunton MJ. Subcutaneous fat thickness is associated with early reoperation and infection after total knee arthroplasty in morbidly obese patients. J Arthroplasty. 2016;31:1788-91.

24. Spicer DD, Pomeroy DL, Badenhausen WE, Schaper LA Jr, Curry JI, Suthers KE, Smith MW. Body mass index as a predictor of outcome in total knee replacement. Int Orthop. 2001;25:246-9.

25. Ethgen O, Bruyere O, Richy F, Dardennes C, Reginster JY. Health-related quality of life in total hip and total knee arthroplasty: a qualitative and systematic review of the literature. J Bone Joint Surg Am. 2004;86:963-74.

26. Seabolt LA, Welch EB, Silver HJ. Imaging methods for analyzing body composition in human obesity and cardiometabolic disease. Ann N Y Acad Sci. 2015;1353:41-59. 